\title{
The Complete Genome Sequence of Southern rice black-streaked dwarf virus Isolated from Vietnam
}

\author{
Thi-Sau Dinh ${ }^{1,2}$, Cuiji Zhou ${ }^{1}$, Xiuling Cao ${ }^{1}$, Chenggui Han ${ }^{1}$, Jialin $\mathrm{Yu}^{1}$, Dawei $\mathrm{Li}^{1}$ and Yongliang Zhang ${ }^{1 *}$

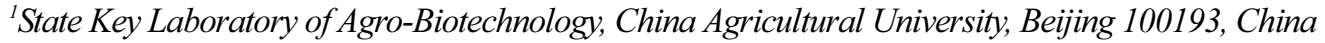 \\ ${ }^{2}$ Faculty of Agriculture Forestry Fisheries, Vinh University, Vinh city, Nghe An province 42000, Vietnam \\ (Received on March 21, 2012; Revised on July 3, 2012; Accepted on July 11, 2012)
}

We determined the complete genome sequence of a Vietnamese isolate of Southern rice black-streaked dwarf virus (SRBSDV). Whole genome comparisons and phylogenetic analysis showed that the genome of the Vietnamese isolate shared high nucleotide sequence identities of over $97.5 \%$ with those of the reported Chinese isolates, confirming a common origin of them. Moreover, the greatest divergence between different SRBSDV isolates was found in the segments S1, S3, S4 and S6, which differs from the sequence alignment results between SRBSDV and Rice black streaked dwarf virus (RBSDV), implying that SRBSDV evolved in a unique way independent of RBSDV. This is the first report of a complete nucleotide sequence of SRBSDV from Vietnam and our data provides new clues for further understanding of molecular variation and epidemiology of SRBSDV in Southeast Asia.

Keywords : phylogenetic analysis, sequence, Southern rice black-streaked dwarf virus, vietnamese isolate

Southern rice black-streaked dwarf virus (SRBSDV) is proposed to be a novel member of the Fijivirus group 2 in the family Reoviridae (Attoui, 2011; Zhang et al., 2008; Zhou et al., 2008). The double-stranded (dsRNA) of SRBSDV contains 10 segments (S1 to S10), which were named in order of decreasing molecular weight (Zhou et al., 2008). SRBSDV was first observed in Yangxi county, Guangdong province in China in 2001. From then on, this disease became one of the most serious viral diseases of rice in southern and central China, causing severe losses in rice production (Wang et al., 2010; Zhou et al., 2010). In 2008, SRBSDV was also detected in maize plants in northern China (Yin et al., 2011). In 2010, the occurrence of SRBSDV disease was firstly reported in rice fields in the Kumamoto Prefecture of Japan (Choi, 2010). In 2009, serious viral rice disease occurred in many northern provinces of

\footnotetext{
*Corresponding author.

Phone) +86-10-62733190, FAX) +86-10-62732012

E-mail) cauzhangyl@cau.edu.cn
}

Vietnam, expanding to a total of 5506 hectares. Of this area, the yields of approximately 3510 hectares were totally lost. The causal agent of the rice dwarf disease in the north of Vietnam has also been identified as SRBSDV (Cuong et al., 2009; Hoang et al., 2011). Further investigation suggested that the outbreak of SRBSDV in Vietnam was associated with rising populations of the white-backed plant hopper (Sogatella furcifera), which is the major vector of SRBSDV (Cuong et al., 2009; Zhou et al., 2008). As planthoppers are constantly displaced by wind currents, the spread of the virus diseases they carry will be inevitable.

Symptoms of SRBSDV infection vary depending on the crop age when infected. Characteristic symptoms include dark-green and wrinkled leaves, incomplete tassel, tumorlike protrusions ending in small enations, tiller formation on the upper parts, up-growing rootlets, and in particular the presence of white to black waxy galls along the major veins of the leaves and culms (Wang et al., 2012; Zhou et al., 2008; Zhou et al., 2010).

Up to now, the complete genome sequence of SRBSDV had been obtained only for three isolates, which originated from Guangdong (GD), Hainan (HN) and Hubei (HB) provinces of China, respectively (Wang et al., 2010). As only partial sequences of segments 4 and 10 from several Vietnamese isolates were investigated and the S10 segment was very conserved among different isolates (Cuong et al., 2009; Hoang et al., 2011), more information about the genome sequence of an SRBSDV isolate from Vietnam will further characterize the geographic and molecular variation of this virus, thus facilitating control and prevention of this disease in Southeast Asia.

Viral genomic dsRNAs were extracted directly from naturally infected field-grown rice plants from Thua Thien Hue province in central Vietnam using the method described previously (Dodds et al., 1984). Primers for cloning segments $\mathrm{S} 1$ to $\mathrm{S} 10$ of Vietnamese isolate were designed to obtain the full length sequence of each genome segment based on the previously reported SRBSDV sequences available in GenBank of NCBI (Wang et al., 2010). Two step RT-PCR was employed to clone cDNA fragments of 
SRBSDV using the primers listed in Supplementary Table 1. The first strand cDNA was synthesized with MMLV reverse transcriptase (Promega, Madison, WI, USA) and subjected to thermocycling amplification using LA Taq DNA polymerase (TaKaRa, Dalian, China). The 3' and 5' terminal sequences of SRBSDV Vietnamese isolate were obtained using the single primer amplification technique (SPAT) as described by Zhou et al. (2008). Briefly, an oligodeoxyribonucleotide primer, P-linker $\left(5^{\prime}-\mathrm{PO}^{4}\right.$-ttccttatg cagctgatcactctGTGTCAGTTCCAGTCACGACA-NH $-\mathrm{NH}_{2}$ '), was ligated to the $3^{\prime}$ ends of both strands of viral dsRNA using T4 RNA ligase (TaKaRa). Oligonucleotides that failed to ligate were removed by spin column chromatography on cellulose nitrate CF-11. Up-stream specific primers for each genome segment were based on the sequence previously determined elsewhere and the downstream general primers were either 5'-tgtcgtgactggaactgacac-3' (complementary to the $3^{\prime}$ end of the P-linker sequence) or 5'ggaactgacacagagtgatcagctgcat-3' (complementary to the 5' end of the P-linker sequence). The PCR products were recovered with QIAquick Gel Extraction Kit (QIAGEN, Hilden, Germany) and cloned into pGEM-T Easy vector (Promega, Madison, WI, USA) according to the manufacturer's instructions, followed by transformation into Escherichia coli Trans-T1 (TransGen Biotech, Beijing, China). In order to obtain the consensus sequences and avoid inconsistencies, three or more clones from each of two separate PCR reactions were sequenced.

The entire DNA sequence of each segment of SRBSDV was then assembled by matching of overlapping sequences. Complete nucleotide sequences of each genomic RNA segment were determined and submitted to GenBank (accession numbers JQ692572-JQ692581 for segments S1 to $\mathrm{S} 10$, respectively). The sequences were then compared to equivalent sequences from other SRBSDV isolates present in GenBank. Identities at nucleotide (nt) and amino acid (aa) levels were calculated using the DNAMAN software (vers. 5.2.2, Lynnon BioSoft, Quebec, Canada). Phylogenetic analysis were conducted with Bioedit (vers. 7.0.4.1) (Hall, 1999) and Clustal W method (Thompson et al., 1994), and visualized with MEGA (vers. 4.1) (Kumar et al., 2008). The phylogeny reconstruction was generated by the neighbor-joining method and displayed using the MEGA 4.1 program, with bootstrap value of 500 replicates.

The viruses included for comparison in this study are Fiji disease virus (FDV) (Harding et al., 2006; McQualter et al., 2004; Soo et al., 1998), Oat sterile dwarf virus (OSDV) (Isogai et al., 1998b), Nilaparvata lugens reovirus (NLRV) (Nakashima and Noda, 1994; Nakashima et al., 1996; Noda et al., 1994), Mal de Río Cuarto virus (MRCV) (Distéfano et al., 2002; Distéfano et al., 2005; Guzmán et al., 2007), Maize rough dwarf virus (MRDV) (Marzachì et al., 1991,

Table 1. Comparisons between the Vietnamese isolate and other plant-infecting fijiviruses

\begin{tabular}{|c|c|c|c|c|c|c|c|c|}
\hline Segment & GD isolate & $\mathrm{HN}$ isolate & HB isolate & RBSDV & MRCV & MRDV & FDV & OSDV $^{\mathrm{a}}$ \\
\hline S1 & $97.9(96.4)^{b}$ & $98.8(99.0)$ & $99.3(99.5)$ & $78.1(86.0)$ & $73.1(79.1)$ & $\mathrm{n} / \mathrm{a}^{\mathrm{c}}$ & $63.1(63.4)$ & $\mathrm{na}$ \\
\hline S2 & $98.8(98.1)$ & $99.3(99.1)$ & $99.7(99.8)$ & $78.6(89.6)$ & $74.1(83.7)$ & $\mathrm{n} / \mathrm{a}$ & $61.0(56.6)$ & $\mathrm{na}$ \\
\hline $\mathrm{S} 3$ & 97.7 (96.7) & $97.6(98.4)$ & $98.4(98.6)$ & $72.7(73.6)$ & $63.7(56.8)$ & $\mathrm{n} / \mathrm{a}$ & $50.7(37.6)$ & $\mathrm{na}$ \\
\hline S4 & $99.2(99.4)$ & $97.5(97.0)$ & $98.7(99.1)$ & $77.9(86.3)$ & $71.0(74.3)$ & $\mathrm{n} / \mathrm{a}$ & $60.8(54.7)$ & $\mathrm{na}$ \\
\hline S5 & $\begin{array}{c}98.4 \\
(98.4,98.5)\end{array}$ & $\begin{array}{c}98.9 \\
(98.4,99.0)\end{array}$ & $\begin{array}{c}99.2 \\
(99.0,98.5)\end{array}$ & $\begin{array}{c}69.4 \\
(68.2,62.4)\end{array}$ & $\begin{array}{c}64.0 \\
(58.6,45.8)\end{array}$ & $\mathrm{n} / \mathrm{a}$ & $\begin{array}{c}47.7 \\
(29.5,-)\end{array}$ & $\mathrm{na}$ \\
\hline S6 & $97.8(96.7)$ & 98.9 (98.9) & 99.2 (98.6) & $68.3(62.7)$ & $55.5(42.5)$ & $\mathrm{n} / \mathrm{a}$ & $36.9(22.9)$ & $\mathrm{na}$ \\
\hline S7 & $\begin{array}{c}99.8 \\
(100,100)\end{array}$ & $\begin{array}{c}99.8 \\
(100,100)\end{array}$ & $\begin{array}{c}99.3 \\
(99.4,99.7)\end{array}$ & $\begin{array}{c}71.7 \\
(80.4,60.2)\end{array}$ & $\begin{array}{c}62.4 \\
(62.9,42.7)\end{array}$ & $\begin{array}{c}73.0 \\
(81.8,61.5)\end{array}$ & $\begin{array}{c}51.8 \\
(51.9,24.2)\end{array}$ & $\begin{array}{c}35.9 \\
(33.4,11.5)\end{array}$ \\
\hline S8 & $99.5(99.8)$ & $99.1(99.2)$ & $99.2(99.3)$ & $72.1(71.9)$ & $60.4(55.5)$ & $71.5(71.1)$ & $46.8(35.8)$ & $39.2(22.5)$ \\
\hline S9 & $\begin{array}{c}99.7 \\
(99.1,100)\end{array}$ & $\begin{array}{c}99.1 \\
(97.4,99.0)\end{array}$ & $\begin{array}{c}98.9 \\
(98.0,98.1)\end{array}$ & $\begin{array}{c}74.2 \\
(77.5,71.8)\end{array}$ & $\begin{array}{c}67.2 \\
(64.6,61.2)\end{array}$ & $\begin{array}{c}74.8 \\
(77.8,73.2)\end{array}$ & $\begin{array}{c}42.5 \\
(34.3,36.7)\end{array}$ & $\begin{array}{c}34.5 \\
(22.8,20.4)\end{array}$ \\
\hline S10 & $99.9(100)$ & $98.8(99.5)$ & $99.5(99.8)$ & $78.1(84.1)$ & $72.0(71.7)$ & 78.4 (83.7) & $53.6(46.0)$ & 41.5 (31.9) \\
\hline
\end{tabular}

${ }^{\mathrm{a}} \mathrm{GD}$ isolate, Guangdong isolate (GenBank accession No. FN563983-FN563988 and EU784840-EU784843); HN isolate, Hainan isolate (GenBank accession No. FN563989-FN563996, EU523359 and EU523360) and HB, Hubei isolates of SRBSDV (GenBank accession No. HM585270-HM585279); MRCV, Mal de Río Cuarto virus (GenBank accession No. AF499925-AF499928, AF395872, AF395873, AY607586, AY607587, AY923115 and DQ023312); MRDV, Maize rough dwarf virus (GenBank accession No. L76560-L76562 and X55701); FDV, Fiji disease virus (GenBank accession No. AY029520, AF049704, AF359556, AF049705, AY029521, AF356083, AY789927, AY297693, AF050086 and AY297694); RBSDV, Rice black-streaked dwarf virus (GenBank accession No. AJ294757, AJ409145-AJ409148, AJ293984, AJ297427, AJ297430, AJ297431 and AJ297433); OSDV, Oat sterile dwarf virus (GenBank accession No. AB011024-AB011027).

${ }^{\mathrm{b}}$ Percent nucleotide identities are shown for the complete segment comparisons and (in brackets) the percentage amino acid identities between the predicted ORFs. The amino acid sequences deduced from S1-S4, S6, S8 and S10 were named P1-P4, P6, P8 and P10, respectively. Similarly, proteins encoded by S5, S7 and S9 were named P5-1/2, P7-1/2 and P9-1/2, respectively.

${ }^{\mathrm{c}} \mathrm{n} / \mathrm{a}$, no sequence available. 
1996), Rice black-streaked dwarf virus (RBSDV) (Wang et al., 2003; Zhang et al., 2001) and three isolates of SRBSDV (Wang et al., 2010) (Table 1). All the viruses mentioned above belong to the genus Fijivirus, and MRCV, MRDV and RBSDV are classified as Fijivirus group 2.

Among the putative structural proteins encoded by SRBSDV, P1, P2 and P4 are putative RNA-dependent RNA polymerase, core protein and outer-shell B-spike protein, respectively; P3 is a putative capping enzyme (Wang et al., 2010; Zhang et al., 2001); P8 and P10 are putative core and major outer capsid proteins, respectively (Isogai et al., 1998a; Wang et al., 2010). Among the putative nonstructural proteins encoded by SRBSDV, P6 is a viral RNA-silencing suppressor ( $\mathrm{Lu}$ et al., 2011), P7-1 is the major constituent of the tubules and has the intrinsic ability to self-interact to form tubules in non-host insect cells (Liu et al., 2011); while P9-1 of SRBSDV was essential for viroplasm formation and viral replication (Jia et al., 2012) (Table 1). Hoang et al (2011) obtained partial sequences of segments S4 and S10 from different Vietnamese SRBSDV isolates and comparisons showed that both of them, especially S10, had high sequence identity among these isolates, suggesting that these segments were not the best alternative for comparison analysis and that more needs to be known about sequence diversity in other segments of the SRBSDV genome. For this reason, we cloned and obtained the full genome sequence of SRBSDV Vietnamese isolate.

Sequence comparison between RBSDV and Vietnamese isolates showed the same segment identities trends as reported previously, of which S1, S2 and S10 are the most conserved while S5 and S6 are the least (Wang et al., 2010). In the phylogenetic analysis using the corresponding regions of all other plant-infecting fijiviruses, all the SRBSDV isolates clustered in one distinct clade well-separated from isolates of other species in the genus (Fig. 1). Comparing the different segments with their counterparts among the 4 SRBSDV isolates indicated that the Vietnamese isolate was highly similar to HB isolate in all 10 genome segments with over $98.4 \%$ nt and $98.0 \%$ aa identities. Sequence alignment between Vietnamese and GD isolates revealed that segments S3 and S6 were most divergent, with $97.7 \%$ and $97.8 \% \mathrm{nt}$ identities and $96.7 \%$ aa identity, respectively. The most sequence divergence between Vietnamese and $\mathrm{HN}$ isolate was located in segments S3 and S4, with $97.6 \%$ and $97.5 \%$ nt identities and $98.4 \%$ and $97.0 \%$ aa identities, respectively. Interestingly, S3 and S4 were the most divergent segments at the nt level whereas S6 and S9 were most divergent at the aa level between the Vietnamese and HB isolates. Moreover, it is worth noting that P9-1, encoded by S9, had a relatively low aa identity between the Vietnamese and $\mathrm{HN}$ isolates (97.4\%) (Table 1).

A previous report showed that S5 and S6 were the most divergent segments between isolates GD and HN (Wang et al., 2010), whereas sequence comparison in our work revealed that the most divergence among the four SRBSDV isolates was found in segments S1, S3, S4 and S6, which also differs from the sequence alignment results between SRBSDV and RBSDV. These results implied a unique evolution pattern of SRBSDV. Recombination or reassortment occurs in many RNA viruses and can be of major
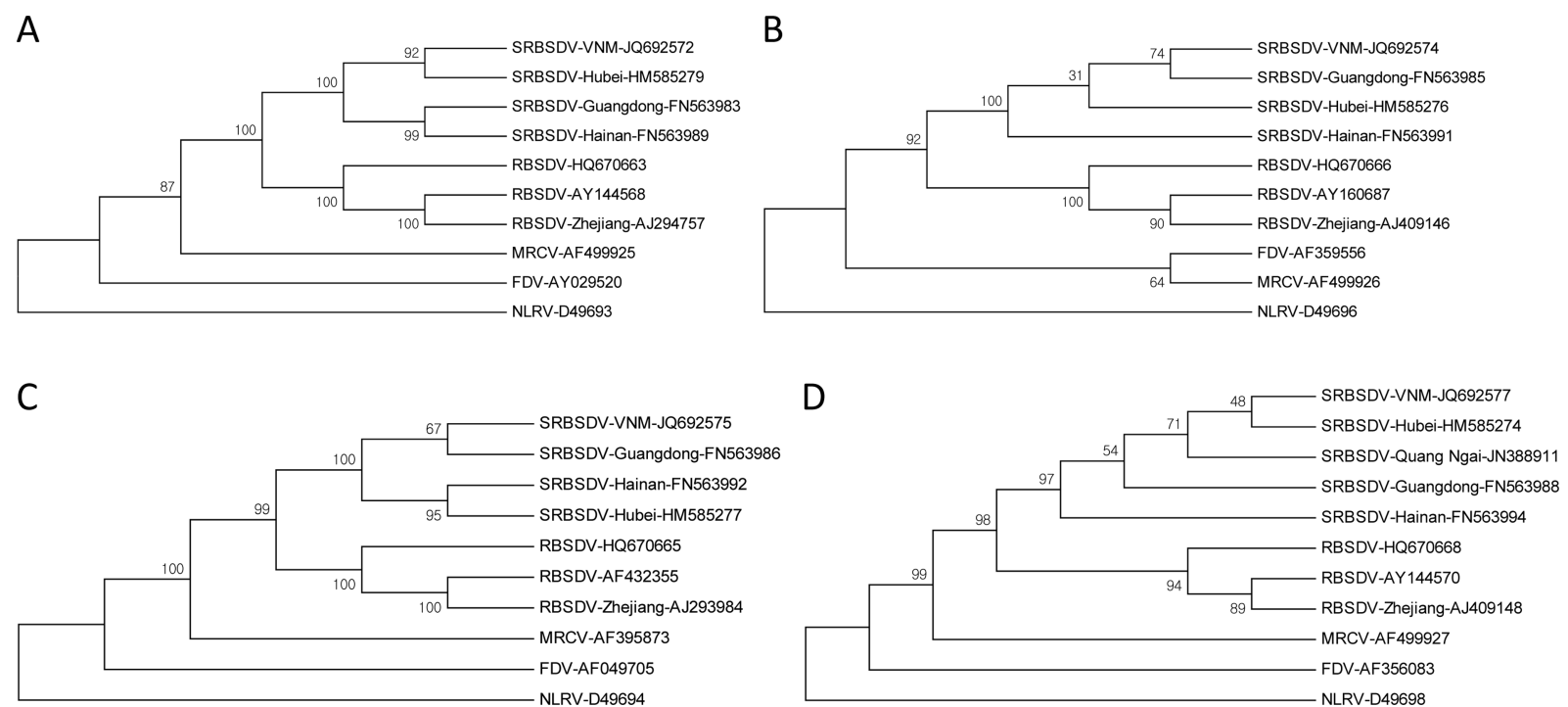

Fig. 1. Phylogenetic tree of SRBSDV Vietnamese (VNM) isolate and other fijiviruses constructed with genomic sequences of segments S1, S3, S4 and S6 (A-D), respectively. The phylogeny reconstruction was generated by the neighbor-joining method and displayed using the MEGA4.1 program, with bootstrap value of 500 replicates. Bootstrap values are shown at nodes. Isolates are indicated in the tree by virus name-accession number. The names of SRBSDV as well as some RBSDV isolates were also listed. 
evolutionary significance (Jiang et al., 2008; Jonson et al., 2011; Miranda et al., 2000; Simon-Loriere and Holmes, 2011). Li et al. (2012) reported that four natural recombinants were detected and the recombinant breakpoints were identified on S10 RNA of 21 RBSDV isolates (Li et al., 2012). Using the software RDP3 (ver. 3.44) (Li et al., 2012; Martin et al., 2010), the sequences of segments S1, S3, S4 and S6 of SRBSDV, respectively, were examined to identify putative recombinants and recombination. Only recombination events that were detected by at least five different methods were accepted. Results showed that recombination events had occurred in all of these four segments of SRBSDV isolates from different geographical regions, indicating that recombination affects several aspects of molecular variation and evolution of SRBSDV. This likely resulted from the frequent migration of the whitebacked plant hopper vector harboring SRBSDV from one place to another and transmission of SRBSDV among host plants such as maize and rice. Overall, the regions which varied most among the four SRBSDV isolates were closely related to its pathogenesis, which involved virus-vectorhost interactions as well as environmental factors. Phylogenetic analysis indicated that SRBSDV isolates from China and Vietnam present different evolutionary distances in the segments S1, S3, S4 and S6, further suggesting the diversity and complexity in the evolution of SRBSDV.

Collectively, we report the first complete genome sequence of an SRBSDV isolate from Vietnam. Our results enriches the data for study of molecular variation and epidemiology of SRBSDV in Southeast Asia. Further investigation of the biological characters needs to be done in order to better illustrate the extent of variation in all 10 genomic RNA segments of SRBSDV and its relationship to variation in pathogenicity of the virus.

\section{Acknowledgments}

This work was partly supported by the National Natural Science Foundation of China (Grant No. 31100115) and the Fundamental Research Funds for the Central Universities of China (Grant No. 2010JS074). We also thank Yongqiang Li for technical assistance in the recombination analysis.

\section{References}

Attoui, H. 2011. Genus Fijivirus. In: Virus Taxonomy-Ninth Report of the International Committee on Taxonomy of Viruses, ed. by A. M. Q. King, M. J. Adams, E. B. Carstens and E. J. Lefkowitz, pp. 563-567. Elsevier, Academic Press, London.

Choi, I. R. 2010. New virus disease found in Japan. http://ricehoppers.net/2010/09/new-virus-disease-found-in-japan/.

Cuong, H. V., Hai, N. V., Man, V. T. and Matsumoto, M. 2009.
Rice dwarf disease in North Vietnam in 2009 is caused by southern rice black-streaked dwarf virus (SRBSDV). Bull. Inst. Trop. Agr., Kyushu Univ. 32:85-92.

Distéfano, A., Conci, L. R., Muñoz Hidalgo, M., Guzmán, F., Hopp, H. E. and del Vas, M. 2002. Sequence analysis of genome segments S4 and S8 of Mal de Río Cuarto virus (MRCV): evidence that the virus should be a separate Fijivirus species. Arch. Virol. 147:1699-1709.

Distéfano, A., Hopp, H. and Del Vas, M. 2005. Sequence analysis of genome segments S5 and S10 of Mal de Rio Cuarto virus (Fijivirus, Reoviridae). Arch. Virol. 150:1241-1248.

Dodds, J. A., Morris, T. J. and Jordan, R. L. 1984. Plant viral double-stranded RNA. Annu. Rev. Phytopathol. 22:151-168.

Guzmán, F., Distéfano, A., Arneodo, J., Hopp, H. E., Lenardon, S. L., del Vas, M. and Conci, L. R. 2007. Sequencing of the bicistronic genome segments $\mathrm{S} 7$ and $\mathrm{S} 9$ of Mal de Río Cuarto virus (Fijivirus, Reoviridae) completes the genome of this virus. Arch. Virol. 152:565-573.

Hall, T. A. 1999. BioEdit: a user-friendly biological sequence alignment editor and analysis program for Windows 95/98/ NT. Nucl. Acid Symp. Ser. 41:95-98.

Harding, R. M., Burns, P., Geijskes, R. J., McQualter, R. M., Dale, J. L. and Smith, G. R. 2006. Molecular analysis of Fiji disease virus segments 2, 4 and 7 completes the genome sequence. Virus Genes 32:43-47.

Hoang, A. T., Zhang, H., Yang, J., Chen, J., Hébrard, E., Zhou, G., Vinh, V. N. and Cheng, J. 2011. Identification, characterization, and distribution of Southern rice black-streaked dwarf virus in Vietnam. Plant Dis. 95:1063-1069.

Isogai, M., Uyeda, I. and Lee, B. 1998a. Detection and assignment of proteins encoded by rice black streaked dwarf fijivirus S7, S8, S9 and S10. J. Gen. Virol. 79:1487-1494.

Isogai, M., Uyeda, I. and Lindsten, K. 1998b. Taxonomic characteristics of fijiviruses based on nucleotide sequences of the oat sterile dwarf virus genome. J. Gen. Virol. 79:1479-1485.

Jia, D., Chen, H., Zheng, A., Chen, Q., Liu, Q., Xie, L., Wu, Z. and Wei, T. 2012. Development of an insect vector cell culture and RNA interference system to investigate the functional role of fijivirus replication protein. J. Virol. doi:10.1128/jvi.0712111.

Jiang, J., Ridley, A. W., Tang, H., Croft, B. J. and Johnson, K. N. 2008. Genetic variability of genome segments 3 and 9 of Fiji disease virus field isolates. Arch. Virol. 153:839-848.

Jonson, M. G., Choi, H. S. and Kim, C. S. 2011. Genetic reassortment of Rice stripe virus RNA segments detected by RT-PCR restriction enzyme analysis-based method. Plant Pathology $J$. 27:148-155.

Kumar, S., Nei, M., Dudley, J. and Tamura, K. 2008. MEGA: a biologist-centric software for evolutionary analysis of DNA and protein sequences. Brief. Bioinform. 9:299-306.

Li, Y., Jia, M., Jiang, Z., Zhou, T. and Fan, Z. 2012. Molecular variation and recombination in RNA segment 10 of rice blackstreaked dwarf virus isolated from China during 2007-2010. Arch. Virol. 157:1351-1356.

Liu, Y., Jia, D., Chen, H., Chen, Q., Xie, L., Wu, Z. and Wei, T. 2011. The P7-1 protein of southern rice black-streaked dwarf 
virus, a fijivirus, induces the formation of tubular structures in insect cells. Arch. Virol. 156:1729-1736.

Lu, Y. H., Zhang, J. F., Xiong, R. Y., Xu, Q. F. and Zhou, Y. J. 2011. Identification of an RNA silencing suppressor encoded by Southern rice black-streaked dwarf virus S6. Sci. Agri. Sinica 44:2909-2917.

Martin, D. P., Lemey, P., Lott, M., Moulton, V., Posada, D. and Lefeuvre, P. 2010. RDP3: a flexible and fast computer program for analyzing recombination. Bioinformatics 26:24622463.

Marzachì, C., Antoniazzi, S., d'Aquilio, M. and Boccardo, G. 1996. The double-stranded RNA genome of maize rough dwarf Fijivirus contains both mono and dicistronic segments. Eur. J. Plant Pathol. 102:601-605.

Marzachì, C., Boccardo, G. and Nuss, D. L. 1991. Cloning of the maize rough dwarf virus genome: molecular confirmation of the plant-reovirus classification scheme and identification of two large nonoverlapping coding domains within a single genomic segment. Virology 180:518-526.

McQualter, R. B., Burns, P., Smith, G. R., Dale, J. L. and Harding, R. M. 2004. Molecular analysis of Fiji disease virus genome segments 5, 6, 8 and 10. Arch. Virol. 149:713-721.

Miranda, G. J., Azzam, O. and Shirako, Y. 2000. Comparison of nucleotide sequences between northern and southern Philippine isolates of rice grassy stunt virus indicates occurrence of natural genetic reassortment. Virology 266:26-32.

Nakashima, N. and Noda, H. 1994. Nucleotide sequence of Nilaparvata lugens reovirus genome segment S8 coding for the major outer capsid protein. J. Gen. Virol. 75:2803-2806.

Nakashima, N., Koizumi, M., Watanabe, H. and Noda, H. 1996. Complete nucleotide sequence of the Nilaparvata lugens reovirus: a putative member of the genus Fijivirus. J. Gen. Virol. 77:139-146.

Noda, H., Nakashima, N. and Omura, T. 1994. Cloning of the Nilaparvata lugens reovirus genome: conserved terminal nucleotide sequences and nucleotide sequence of genome segment S10. J. Gen. Virol. 75:221-226.

Simon-Loriere, E. and Holmes, E. C. 2011. Why do RNA viruses recombine? Nat. Rev. Microbiol. 9:617-626.

Soo, H. M., Handley, J. A., Maugeri, M. M., Burns, P., Smith, G.
R., Dale, J. L. and Harding, R. M. 1998. Molecular characterization of Fiji disease fijivirus genome segment 9. J. Gen. Virol. 79:3155-3161.

Thompson, J. D., Higgins, D. G. and Gibson, T. J. 1994. CLUSTAL W: improving the sensitivity of progressive multiple sequence alignment through sequence weighting, positionspecific gap penalties and weight matrix choice. Nucleic Acids Res. 22:4673-4680.

Wang, Q., Yang, J., Zhou, G. H., Zhang, H. M., Chen, J. P. and Adams, M. J. 2010. The complete genome sequence of two isolates of southern rice black-streaked dwarf virus, a new member of the genus Fijivirus. J. Phytopathol. 158:733-737.

Wang, Z., Yu, D., Li, X., Zeng, M., Chen, Z., Bi, L., Liu, J., Jin, L., Hu, D. and Yang, S. 2012. The development and application of a dot-ELISA assay for diagnosis of Southern rice black-streaked dwarf disease in the field. Viruses 4:167-183.

Wang, Z. H., Fang, S. G., Xu, J. L., Sun, L. Y., Li, D. W. and Yu, J. L. 2003. Sequence analysis of the complete genome of rice black-streaked dwarf virus isolated from maize with rough dwarf disease. Virus Genes 27:163-168.

Yin, X., Xu, F., Zheng, F., Li, X., Liu, B. and Zhang, C. 2011. Molecular characterization of segments S7 to S10 of a southern rice black-streaked dwarf virus isolate from maize in northern China. Virol. Sin. 26:47-53.

Zhang, H. M., Chen, J. P. and Adams, M. J. 2001. Molecular characterisation of segments 1 to 6 of Rice black-streaked dwarf virus from China provides the complete genome. Arch. Virol. 146:2331-2339.

Zhang, H. M., Yang, J., Chen, J. P. and Adams, M. 2008. A blackstreaked dwarf disease on rice in China is caused by a novel fijivirus. Arch. Virol. 153:1893-1898.

Zhou, G. H., Wen, J. J., Cai, D. J., Li, P., Xu, D. L. and Zhang, S. G. 2008. Southern rice black-streaked dwarf virus: A new proposed Fijivirus species in the family Reoviridae. Chin. Sci. Bull. 53:3677-3685.

Zhou, G. H., Zhang, S. G., Zou, S. F., Xu, Z. W. and Zhou, Z. Q. 2010. Occurrence and damage analysis of a new rice dwarf disease caused by Southern rice black-streaked dwarf virus. Plant Protec. 36:144-146. 